\title{
LIVING THROUGH LOSS: QUESTIONS AND ANSWERS ABOUT GRIEF AND BEREAVEMENT
}

\author{
Robert A. Neimeyer* \\ University of Memphis
}

\begin{abstract}
The field of grief therapy is rapidly evolving, as new theories, models and research findings inspire new understandings of loss and how people accommodate it. This article summarizes some of these contemporary developments, emphasizing the search for meaning in bereavement, and illustrates how these fresh perspectives can offer guidance to real people seeking consultation on how to manage very real losses under complicating circumstances. Nurses occupy many roles that bring them into contact with death and grief, leaving them well positioned to extend knowledgeable and compassionate care for patients and families facing such existential transitions.
\end{abstract}

KEYwORDS: nurses's role, grief, bereavement care, loss.

\section{VIVIENDO EL DUELO: PREGUNTAS Y RESPUESTAS \\ SOBRE LA PÉRDIDA Y EL DUELO}

\section{RESUMEN}

El campo de las terapias de duelo está evolucionando rápidamente, mientras las nuevas teorías, modelos y hallazgos de investigación inspiran nuevas comprensiones sobre la pérdida y sobre cómo las personas se adaptan a ella. Este artículo resume algunos de estos desarrollos contemporáneos enfatizando la búsqueda de sentido en el duelo, e ilustra cómo estas nuevas perspectivas pueden ofrecer orientación a las personas que buscan asesoramiento para enfrentar las pérdidas bajo circunstancias complicadas. Las enfermeras por su trabajo están en contacto con la muerte y el dolor, por lo que ocupan una posición privilegiada para extender el cuidado compasivo e informado tanto a lo pacientes como a las familias que enfrentan tales transiciones existenciales.

Palabras clave: rol de las enfermeras, cuidados del duelo, pérdida. 
The publication of an important new journal in the field of nursing is a welcome development, given the vast range of roles that nurses play in caring for children and adults, in settings that range from delivery rooms and neonatal intensive care units through emergency departments and surgical theatres to geriatric facilities and palliative care services. And because many of these settings are liminal environments in which life meets with death, despite the best efforts at treatment provided by the interdisciplinary team, it is equally welcome that this inaugural issue is devoted to end-of-life care and bereavement. My modest goal in this brief article is to suggest the relevance of contemporary psychological theory, research and practice to nursing care in such contexts, particularly for those nurses engaged in patient education, family oriented practice, and roles that encourage not only technical competence in providing care for ailing bodies, but also care for the human beings who suffer emotionally and spiritually in anticipation of or in response to the death of a member of the family, and who require more than the competent administration of medication and comfort care.

Specifically, I will briefly sketch three current theories of grief that are supported by a growing evidence base, and that carry important implications for bereavement care, whatever the discipline of the practitioner. I will then break with academic convention and engage not other researchers, but rather the mourners themselves, and the nurses and other professionals who work directly with them. To do so I will draw upon the large trove of questions that both groups have directed to me for consultation, and share my responses to each in an unedited manner. This means that I have endeavored to speak compassionately but knowledgeably as a bereavement scholar, and also plainly and practically as a counselor with one small window of opportunity to offer consolation, perspective and actionable advice to people who greatly, often desperately, need it. ${ }^{1}$ In doing so, I will avoid the usual custom of extensive scientific justification of points made, although I will offer advice that is compatible with both the burgeoning research literature and with my 40 years of working alongside the bereaved as a grief therapist in the wake of life-altering loss. I hope that the responses provide perspective and encouragement for the readers of this journal as well, as they too commonly have only brief, but potentially profound, opportunities to extend to patients and their families useful professional companioning at this critical juncture.

* PhD. University of Memphis, USA and Portland Institute for Loss and Transition. Address correspondence to neimeyer@portlandinstitute.org.

1 The source of these questions and answers is AfterTalk (www.aftertalk.com), an innovative grief support site that offers expressive writing tools, inspirational quotes and hospice-oriented resources for memory archiving, all as free services to mourners and the professionals working with them. My "Ask Dr. Neimeyer" advice column on that site has proven to be one of its most frequently accessed features, and speaks to the great need of families for informed and compassionate guidance through life's most troubling transitions. 
Only a few short years ago the field of bereavement care was marked by substantial consensus. Theorists working within a psychodynamic tradition subscribed to Freud's (Freud, 1917/1957) foundational assumption that healthy mourning required griefwork, in the form of a painful review and relinquishment of one's "bondage" to the deceased, a process of "letting go" termed decathexis. Accordingly, practitioners concentrated largely on encouraging the bereaved to give voice to their anguish, explore it in individual or group support contexts, and ultimately "move on" with their lives, withdrawing emotional energy from the one who had died in order to invest it in living relationships. For many nurses and other professional caregivers - perhaps especially those working in the end-of-life context in which it was formulated- Kübler-Ross's (1969) model of the "stages" of grief, beginning with denial, and progressing through anger, bargaining and depression on the way to acceptance or recovery, provided an intuitive road map for such work. With little research on the actual course of grieving and the factors that shaped it, serious dissent from this dominant paradigm was rare for much of the $20^{\text {th }}$ century. As a result, most workers involved in palliative care, hospice and bereavement support were trained in fairly generic understandings of grief and its psychological dimensions, with the presumption that its facilitation simply required patient support for "time to heal all wounds."

But these traditional views of mourning are being challenged on many fronts in contemporary thanatology. For example, longitudinal studies of bereavement adaptation fail to provide much support for a model of stages of emotional response to grief (Maciejewski, Zhang, Block, \& Prigerson, 2007). One study of a large cohort of bereaved individuals suffering the death of a loved one by natural causes found that "acceptance" of the death, presumably the final stage of adaptation, actually was the predominant response of survivors from the earliest weeks of loss, with depression and yearning being the strongest of the "negative indicators" of grief-related distress across two years of bereavement, while symptoms of denial and anger occurred at consistently low levels. In contrast, for those whose loved ones died by accident, homicide or suicide, disbelief did predominate in early weeks, with anger and depression eclipsing yearning for the loved one across much of the grieving period (Holland \& Neimeyer, 2010). Such findings argue against the relevance of "one size fits all" models of mourning, as well as for the importance of evaluating popular models against actual data on adaptation to loss. Furthermore, researchers present compelling data that suggest that, at least after spousal loss, not everyone appears to go through a painful process of depression and mourning. Some spouses seem to begin coping well within a matter of weeks, and some even experience apparent relief following their partner's lengthy illness or a conflictual marriage (Bonanno, 2004; Bonanno, Wortman, \& Nesse, 2004). Such findings argue that traditional models of grief have underestimated people's resilience in the face of loss, and indeed evidence suggests that many "normal" grievers will adapt well to loss over a period of several months, with or without formal grief counseling (Currier, Neimeyer, \& Berman, 2008). 
Likewise, the idea that decathexis or "letting go" of the loved one is central to the process of grieving is being challenged by scholars who argue that the establishment of ongoing bonds with the deceased is both healthier and more normative across human cultures than the notion of detachment from the deceased (Klass, Silverman, \& Nickman, 1996; Klass \& Steffen, 2018; Rubin, 1999). Indeed, evidence suggests that maintaining an emotional bond with the loved one may be comforting or distressing, depending on whether mourners have been able to "make sense" of the loss (Neimeyer, Baldwin, \& Gillies, 2006), and as a function of their level of security in important attachment relationships (Smigelsky, Bottomley, Relyea, $\&$ Neimeyer, 2019). Accordingly, theorists espousing a Two-Track Model of Bereavement (TTMB) (Rubin, Malkinson, \& Witztum, 2011) advocate assessing difficulties occurring on both the track of biopsychosocial functioning (e.g., depression, anxiety, work performance) and the track of the relationship to the deceased (e.g., how the loved one is held in memory, residual feelings in the relationship, ritual practices for maintaining his or her presence in the mourner's life). This then permits careful targeting of problems in both domains in the context of an attachment-informed grief therapy (Kosminsky \& Jordan, 2016).

In the wake of growing skepticism about traditional models of mourning, other new theories also have been proposed. One such model is the Dual Process Model of coping with bereavement (DPM) formulated by Stroebe and Schut (2010), which argues that normal grief involves an oscillation between confronting the loss (Loss Orientation) and compartmentalizing it so that the mourner can attend to the life changes necessitated by the death (Restoration Orientation). This model describes mourning as a cyclical rather than linear and stage-like process, as the mourner repeatedly revisits the loss and its associated emotions, strives to reorganize the relationship to the deceased, and to take on new roles and responsibilities necessitated by a changed world. This formulation also suggests that the inability to distract oneself from or avoid grief may be as much a sign of complication as the inability to confront it. Giving balanced attention to both loss and life in the context of bereavement therefore becomes a high priority.

Yet another theoretical development is the emergence of a meaning reconstruction approach to grief (Neimeyer, 2019, 2001). In this view, bereavement is viewed as challenging the survivor's self-narrative, the basic organization of life events that allows people to interpret the past, invest in the present and anticipate the future. Recent research documents that a painful search for meaning in the near aftermath of loss forecasts more intense grief months and years later, whereas the capacity to find significance of the loss predicts greater long-term well-being (Coleman \& Neimeyer, 2010). Moreover, a struggle to find meaning in the loss accounts for the impact of several prominent "risk factors" for prolonged and intense grief (such as death of a spouse, low social support, insecure attachment and violent death bereavement) over time, especially in the presence of high levels of rumination (Milman et al., 2019). Likewise, studies of parents who have lost a child have documented that a struggle to make sense of the loss accounts for greatly more of the intensity of the parents' grief than such objective factors as the passage of time, the cause of death, or the parents' gender (Keesee, Currier, \& Neimeyer, 
2008). With support for this basic proposition from dozens of studies of bereaved young people, parents, and older adults suffering the death of loved ones to both natural and violent causes, a meaning reconstruction approach therefore emphasizes the importance of helping the bereaved (a) process the "event story" of the death and its implications for their lives, and (b) access the "back story" of their relation to the deceased, to restore a sense of attachment security and to resolve relational issues that interfere with a sustaining and meaningful connection to the one who has died (Neimeyer, 2019).

With these models and findings as a backdrop, I now turn to the painful and practical questions raised by the bereaved themselves, many of whom are struggling with very complicated losses of equally complicated relationships. In addition, I will sample the requests for consultation on the part of nurses and other health care providers that suggest the usefulness of contemporary grief theory, research and practice when patient and family needs are great, and practitioners feel stuck or uncertain about how to move forward.

\section{WHEN GRIEF FINDS VOICE: QUESTIONS AND ANSWERS ABOUT COPING WITH BEREAVEMENT}

\section{Dear Dr. Neimeyer,}

I lost my dearest husband 3 months ago after almost 8 years of battling cancer. Our attachment deepened even more when he was diagnosed in the year 2011 since we got to be with each other 24/7. This perhaps is the reason why until now I can't seem to move on. It's as if time doesn't heal all wounds.

Visiting his grave has become a part of my daily routine. I try to get busy with other things but he is always in my thoughts. Am I suffering from depression? I have done almost everything to ease the pain of losing him... I have made a memorial table in loving memory of him... I have collected photos to create a memorial album, etc.

I find solace in the chirps of the birds, the drizzling water from the fountain, and the sounds from the wind chimes. But I'm really torn into pieces. I am heartbroken... Life seems meaningless without my beloved...

Praying and hoping that you could help me get through this, Doc.

- RenAta

Dear Renata,

To experience keen heartbreak just three months after the death of your life partner is certainly a common experience with which countless bereaved spouses can identify. And it is easy to imagine, as you suggest, that the intense bonding required to negotiate his lengthy illness could have made a close relationship all that much closer. If, as your " $24 / 7$ " description of togetherness implies, pulling 
together to contend with his cancer perhaps inevitably also entailed pulling away from others, this too would tie your heartstrings so fully to his that severing them could be especially anguishing, almost like being surgically separated from a Siamese twin. And you are right that time alone does little to heal such wounds, as studies of complicated and prolonged grief reactions tell us. Instead, it is what we do with the time that counts.

And so what might you do with the time to help you adapt to this changed world into which his death has thrown you? Some ideas are provided by contemporary understandings of grief. For a visual aid of one useful theory, adapted from the Dual Process Model of Coping with Bereavement (DPM) by Maggie Stroebe and Henk Schut, try this:

1. Draw a wide oblong oval on a sheet of paper, from side to side. Label this "Everyday Life Experience."

2. Then, within this oval, add two egg-like shapes standing up, one near either end, with a gap between them. Label the one on the left "Loss" and the one on the right "Life."

3. Finally, starting near the top of the eggs, draw a zig-zag line going back and forth between them, from top to bottom. Label this "Pendulum Swing."

Now sit back and take a look at the "Map of Mourning" that you've drawn. Imagine that the Loss sphere contains the raw pain of grief, the loneliness, the longing, the attempt to reconnect with your husband, to restore the bond. And imagine that the Life sphere contains everything else: buying groceries, relating to friends and family, pursuing projects, working, trying new things, taking on new roles. Both are important. Both are part of grief. The pendulum swing between them -even if initially much more time is spent in the Loss orientation- reminds us that we naturally are drawn to and require both. Perhaps at first we have only a few moments of "time out" from our grief when engaged in something that requires our concentration, but these moments are crucial to embrace, nurture, and enlarge, to provide a natural counterbalance to the absorption in loss. At the heart of the DPM is an audacious notion: that we make progress through grief when we give ourselves permission, even encouragement, to make time to grieve... and time not to. We need the former to learn how to love someone in his or her physical absence, and we need the latter in order to learn to live differently, but with meaning in the changed world.

Now make an honest inventory of all of the thoughts, actions, and projects you undertake in an average day or week. Of those you mention, nearly all focus on the left side of the model, falling within the Loss orientation: visiting the grave daily, constructing a memorial table, organizing a memorial album, etc. No doubt each is an act of love, and is deeply meaningful. But only "trying to get busy with other things" falls into the right side of the map, the Life orientation, and the way you phrase it suggests that the things you try to get busy with have much less meaning for you. To balance the pendulum, what might you add consciously to that side of the model? How about visiting a new or beloved place daily with a special friend? Rearranging a table top to feature a display of arts or crafts that you find 
beautiful? Making an album of new photographs you take yourself that touch or inspire you, such as the birds, fountain, or natural scenes to which you are drawn? The idea would be to promote a natural back-and-forth between loss and life, grief and growth, in a way that carries you forward in both domains.

One of the subtler implications of the DPM is that adapting to loss is not a straight arrow that moves from left to right on the map; it's rarely that easy. Loss is a part of our everyday life experience as bereaved people... but only a part. With intention, tenacity, and good company we can also refresh and reinvent ourselves by giving the Life side of the equation equal time. Ask yourself if your husband would want that for you. If the answer is yes, you may owe it to him as much as to yourself and others who care about you to move forward by stepping first with your left foot, and then with your right, shifting your balance between Loss and Life, as naturally as walking toward a self-set goal... knowing that you will take your husband along with you.

\section{- Dr. Neimeyer \\ Dear Dr. Neimeyer,}

I lost my 12-year-old daughter Madison three weeks ago today. Earlier this summer she was diagnosed with a rare autoimmune disorder but was in good health -at least we thought. But when she got her first treatment, within a week she was in the intensive care unit of the hospital and then we had to make the heart-wrenching decision to take her off the machines two weeks later, because her heart was severely damaged. My question is this: I have read about the steps of grieving, but I am so all over the place. I feel guilty, like I failed her as a Mom. I'm sad, and have difficulty eating and sleeping. Is this normal for sudden loss and since it just happened? I do not even know what to do or how to grieve. I'm just so confused!

\section{- Felicia \\ Dear Felicia,}

First, throw out everything you've read about "the steps of grieving." Your steps will be your own, not the idealized progression that begins with denial, advances to bargaining, shifts to anger, collapses into depression, and then progresses toward acceptance. As you say, you "are all over the place," and the map you might draw of your grief journey will surely contain many strong emotions (like guilt, but also yearning, anxiety, despair, and more), all in a confusing an unstable tumult of feelings. Your world has been violated, your daughter tragically taken from you, and all others who love her. Profound grief is an appropriate response to such a loss.

So the immediate question is what you need now to weather this hurricane-force storm of anguish. To begin with, very basic self-care may be an early priority: eating even when you don't feel like it, getting some temporary help from your doctor to get some restorative nightly sleep, striving to find your way back 
to basic routines. In addition, many parents in the throes of anguish over losing a child find solace in one another's company, as they wrestle with similar questions and feelings, and seek the companionship of the only people who really "get it" one another. Groups like The Compassionate Friends and similar mutual support groups that can be found readily on the Internet can provide a great deal of tangible assistance and information that can reduce the confusion and sense of aloneness that mothers and fathers contending with this uniquely hard loss face. And if you find after some months that you seem to be heading in the wrong direction, in the sense of falling apart rather than gradually pulling yourself together, or if family relationships begin to suffer serious damage as a result of different ways of coping, then these same bereaved parents are often a good source of referral information to mental health professionals who can help you with the hard challenges of making sense of this tragedy and your life in its aftermath.

Above all, remember that you did not rob Madison of the life she deserved; a rare and random medical condition did that. Your task now is to carry on for your family and for her, keeping her close in a heart that mends and enlarges to contain both life and loss, while still making a place for her.

\section{- Dr. Neimeyer \\ Dear Dr. Neimeyer,}

I am a psychiatric nurse and therapist, and I attended one of your workshops a couple years ago. I have a question for you related to a client I am currently treating. This client is a man in his mid 20s and his father died when my client was in his mid-teens. His father died from complications from drinking too much. My client worries he should not be grieving anymore and also worries he will forget his father. The worry that he will forget his father is quite distressing for him. Can you provide some general guidance on how I can work with this fear of forgetting? Additionally, if you can recommend any articles to read on this topic that would also be wonderful. Thank you,

\section{- Carmen N., RN MFT}

Dear Carmen,

My brief response to your case-based query is that the premature death of your client's father and his son's fear of forgetting him speaks to our common need to conserve a bond with the deceased rather than to "let them go." In our contemporary, secular age, rituals of continuity and transition once provided by spiritual and cultural practices of remembrance often are radically condensed or relinquished altogether, and we are left needing to invent them in quite personal ways for ourselves. In this, therapy can provide assistance by joining with clients in imagining how we might keep our loved ones stories alive -especially their preferred stories of proud or close moments shared with our clients, rather than only their stories 
of brokenness, conflict, or absence. Of course, the painful parts of the story -including in this case the destructive drinking- must also be acknowledged candidly, but I would join the client in seeking to restore to memory and perhaps to some form of public telling the preferred stories as well. You might find a variety of resources helpful in envisioning this, from professional books like Klass and Steffen's "Continuing bonds in bereavement" published recently by Routledge, to sensitive popular movies like "Coco," which traces a young boy's efforts to embrace imperfect family ties while also finding his own unique way in the world.

All of this is to say that nearly anything that honors our loved one helps restore a constructive bond, and in this sense helps as well with our grief by restoring connection in the form that is sustainable now. Finding and displaying on one's computer or phone's home screen a picture of your client and father together (rather than the father alone), sharing stories about times with dad in person or in online memorials, performing small acts of kindness such as paying in advance for the order of the next person in the line at the local cafe and doing so in the father's memory, or undertaking some form of legacy project, such as constructing a scrapbook of shared memories or contributing time to a cause that might be relevant to the father (such as speaking about problems of substance abuse on campus) could all serve this function of constructing and honoring an enduring bond with dad. Such meaningful actions take a strong stand against forgetting, and remind us that in a life that in which we sometimes exercise far too little control over events, in other ways choice and agency are fully available to us - including in how we continue to love someone in his absence.

- Dr. Neimeyer

Dear Dr. Neimeyer,

I lost my oldest son nearly 8 years ago to suicide at the age of 24 . He shot himself in our home. Friends and people from church were very kind to us after it happened. We have three other sons. They are all grown now, but one has had a drug problem and is currently incarcerated. We have stayed in our home as it was my husband's childhood home and he didn't want to leave. Anyway, now it seems as though friends and family avoid us, and I'm wondering if it would have been better if we had moved? My husband and I are raising a granddaughter, but outside of that, we don't connect either. I feel very isolated and misunderstood. Any advice would be helpful.

- JOANa

Dear Joana,

Your direct and honest account presents such a litany of loss, from the vivid and traumatic death of one son in your home, through the heartbreak of another's drug abuse and incarceration, to the seemingly unexplained thinning of relations 
with friends, family, and even your spouse. As much joy and meaning as raising your granddaughter might bring, I can well imagine the sense of aloneness that otherwise pervades the house, which seems in too many ways emptied of the life and love it must once have held.

No "quick fix" can make this sad scenario instantly better, so I won't insult you by offering you one. But I am moved to offer at least a few principles that might help as you navigate this sea of losses, and try to find your way back to safe harbor and human companionship. Think of them as possible responses to the sometimes stark and sometimes subtle grief you encounter, and consider whether one or more of them feels like a step that you are (more than) ready to take.

1. Acknowledge the stigma, and push back against it. Suicide loss in particular tends to be heavily stigmatized and "disenfranchised," in the sense of being uncomfortably ignored or invalidated by much of the social world. In your case, you were fortunate to receive a much kinder and more compassionate response from your church and community after your son's death, but it is often the case that the outpouring of support that survivors receive in the immediate aftermath of tragic death evaporates after a few weeks, leaving mourners with a "silent story" of suffering that cannot easily be shared. It is for this reason that Survivors of Suicide groups can offer uniquely valuable mutual support for people in your position who might well be troubled by this traumatic event even many years later. Trauma-informed therapies can address residual images and feelings, and resources like those offered by the American Foundation of Suicide Prevention and similar international organizations to long-term survivors can often pick up where local and limited support leaves off.

2. Voice the unspoken losses, and find an audience for them. Your other son's incarceration, and very likely a turbulent history of drug use that preceded it, must have introduced their own losses, perhaps in the form of a loss of control over the situation, the loss of trust in your son, and perhaps even the loss of hope for a meaningful life you must have harbored for him in more innocent years. In facing such ambiguous losses, it is often helpful to "name them and claim them," putting yourself in a quiet, reflective frame of mind, during a period of privacy, with your phone turned off, as you ask yourself repeatedly and honestly, "What have I lost?" Then pause, and patiently let the answer come to you, writing it down in a word or phrase. Then repeat the question, and wait for the next answer, recording it, too, when it comes. Do this 10 times. Then survey your list and ask, "What do I most need in relation to each of these losses? And what would be the first step I could take toward getting this?" Take action on three of these steps, and in the loss journal that you have begun, record the results of your efforts. Where you see some signs of success, do more of that, or ask yourself, "What's the next step here?" Where you are disappointed by the results, learn from them, and ask, "What step might I try instead?" 
3. Re-weave the ties that bind. There was a time that you were held in loving arms, in a tender gaze, in the caring concern of a faith community and friendship circle. Spend some time reflecting on what happened, without resorting the morally satisfying, but ultimately futile tactic of merely blaming the loss of this connection on the failings of others... true though this may often be. Instead, try to understand the thinning or sundering of these ties usefully -what do they teach you about what is required to keep a relationship in good repair? Consider how you might restore, renew or replace strained or broken connections by reaching out to others in their own pain or grief -which inhabits every life, in a degree large or small. Or is a bolder step needed, in the form of joining a new church congregation, or simply engaging a community of people who share an interest (perhaps in the arts, cooking, a book club or civic organization) you once indulged, but in your years of suffering, have allowed to atrophy? And perhaps most centrally, take the risk of speaking frankly to your husband about both your appreciation for his co-parenting, and the lonely part of you that misses the intimacy and closeness you once shared. Whether with the help of a couples therapist or through creative reengagement and the cultivation of shared interest, strive to recover some of what you have lost, so that the rest does not have to be borne alone.

- Dr. Neimeyer.

\section{CODA}

The above questions and answers about life-altering loss represent only a small sampling of real exchanges with real people suffering very real losses, under a variety of complicating circumstances and relationships. Clearly, no simple answer can be given to the profound disorientation, yearning, fear, loneliness and anguish that such losses engender, and my responses at best suggest the importance of self-compassion, courage, companionship and concrete action steps to reclaim lives of meaning in the wake of tragic life transitions. In seeking grief counseling or therapy rather than brief consultation, those who are contending with profound brokenness can often find a professional fellow traveler on this journey, one who can accompany them on the sometimes long quest to reconstruct their lives. But both experience and life also tells us that most of the bereaved do not seek professional therapy, but instead make use of caring and wise listeners where they find them including in the hospitals, long-term care facilities, hospice and palliative care programs and public health settings in which nursing plays a crucial role. I therefore hope that a few of the ideas summarized in this brief article will prove useful to you as you encounter loss in the lives of the patients and families for whom you care, so that they might feel more deeply understood and supported in their journey. 


\section{ENDNOTE}

Readers interested in further professional training in grief counseling and therapy from a meaning-oriented perspective are encouraged to explore the website of the Portland Institute for Loss and Transition, which offers workshops and certification programs in four major world regions and in major world languages, including Spanish. Simply navigate to www.portlandinstitute.org.

RECIBIDO: 4-5-2019; ACEPTADO: 9-7-2019 


\section{REFERENCES}

Bonanno, G.A. (2004). Loss, trauma and human resilience. American Psychologist, 59, 20-28.

Bonanno, G.A., Wortman, C.B., \& Nesse, R.M. (2004). Prospective patterns of resilience and maladjustment during widowhood. Psychology and Aging, 19, 260-271.

Coleman, R.A., \& Neimeyer, R.A. (2010). Measuring meaning: Searching for and making sense of spousal loss in later life. Death Studies, 34, 804-834.

Currier, J.M., Neimeyer, R.A., \& Berman, J.S. (2008). The effectiveness of psychotherapeutic interventions for the bereaved: A comprehensive quantitative review. Psychological Bulletin, 134, 648-661.

Freud, S. (1917/1957). Mourning and melancholia. In J. Strachey (ed.), The Complete Psychological Works of Sigmund Freud (pp. 152-170). London, England: Hogarth Press.

Holland, J.M., \& Neimeyer, R.A. (2010). An examination of stage theory of grief among individuals bereaved by natural and violent causes: A meaning-oriented contribution. Omega, $61,105-122$.

Keesee, N.J., Currier, J.M., \& Neimeyer, R.A. (2008). Predictors of grief following the death of one's child: The contribution of finding meaning. Journal of Clinical Psychology, 64, $1145-1163$.

Klass, D., Silverman, P.R., \& Nickman, S. (1996). Continuing bonds: New understandings of grief. Washington: Taylor \& Francis.

Klass, D., \& Steffen, E. (eds.). (2018). Continuing bnds in bereavement. New York: Routledge.

Kosminsky, P., \& Jordan, J.R. (2016). Attachment informed grief therapy. New York: Routledge.

Kubler-Ross, E. (1969). On death and dying. New York: Macmillan.

Maciejewski, P.K., Zhang, B., Block, S. D., \& Prigerson, H.G. (2007). An empirical examination of the stage theory of grief. Journal of the American Medical Association, 297, 716-723.

Milman, E., Neimeyer, R.A., Fitzpatrick, M., MacKinnon, C.J., Muis, K.R., \& Cohen, S.R. (2019). Rumination moderates the role of meaning in the development of prolonged grief symptomatology. Journal of Clinical Psychology. doi: 10.1002/jcp.22751.

Neimeyer, R.A. (2019). Meaning reconstruction in bereavement: Development of a research program. Death Studies, in press. doi: org/10.1080/07481187.2018.1456620.

Neimeyer, R.A. (ed.). (2001). Meaning reconstruction and the experience of loss. Washington, D.C.: American Psychological Association.

Neimeyer, R.A., Baldwin, S.A., \& Gillies, J. (2006). Continuing bonds and reconstructing meaning: Mitigating complications in bereavement. Death Studies, 30, 715-738.

Rubin, S.S., Malkinson, R., \& Witztum, E. (2011). Working with the bereaved. New York: Routledge.

Smigelsky, M.A., Bottomley, J.S., Relyea, G., \& Neimeyer, R.A. (2019). Investigating risk for grief severity: Attachment to the deceased and relationship quality. Death Studies, in press.

Stroebe, M., \& Schut, H. (1999). The Dual Process Model of coping with bereavement: Rationale and description. Death Studies, 23, 197-224.

Stroebe, M., \& Schut, H. (2010). The Dual Process Model of Coping with Bereavement: A decade on. Omega, 61, 273-289. 
